\title{
Recent changes in the Labrador Sea Water within the Deep Western Boundary Current Southeast of Cape Cod
}

\author{
Beatriz Peña-Molino ${ }^{\mathrm{b}, 1, *}$, Terrence M. Joyce ${ }^{\mathrm{b}}$, John M. Toole ${ }^{\mathrm{b}}$ \\ ${ }^{a}$ ACE CRC University of Tasmania, Private Bag 80, Hobart Tasmania 7001, Australia \\ ${ }^{b}$ Woods Hole Oceanographic Institution, 360 Woods Hole Road, Woods Hole, 02543 \\ Massachusetts, USA
}

\begin{abstract}
Water properties measured by the central mooring in the Line $\mathrm{W}$ mooring array southeast of Cape Cod document a large character shift during the period of November 2001 to April 2008. The observed temperature, salinity and planetary potential vorticity (PPV) anomalies manifest changes in the formation region of the water masses present at Station $\mathrm{W}$, specifically upper Labrador Sea Water (uLSW), deep Labrador Sea Water (dLSW) and Overflow Water (OW). During the observation period, the minimum in the PPV anomaly field relative to the record mean PPV profile migrated from $1500 \mathrm{~m}$, where it was originally found, to $700 \mathrm{~m}$. Temporal changes in the vertical distribution of temperature and salinity were correlated with the PPV changes. This suggests a dLSW-dominated first half of the record, versus an uLSW-dominated second half. The structure of these anomalies is consistent with observations within the Labrador Sea, and their transit time to Line $\mathrm{W}$
\end{abstract}

\footnotetext{
${ }^{*}$ Corresponding author

Email addresses: beatriz.penamolino. @utas.edu.au (Beatriz Peña-Molino), tjoyce@whoi.edu (Terrence M. Joyce), jtoole@whoi.edu (John M. Toole)
} 
agrees well with tracer-derived times for signals spreading along the western boundary. In that context, the observed water properties at Line $\mathrm{W}$ in the early 2000s reflected the intense deep convection in the Labrador Sea in the mid 1990s, with less intense convection subsequently affecting lighter isopycnals. The observed velocity field is dominated by high-frequency (periods of days to months) fluctuations, however, a fraction of the velocity variability is correlated with changes in water mass properties, and indicate a gradual acceleration of the southwestward flow, with a corresponding increase in Deep Western Boundary Current transport.

Keywords: Deep Western Boundary Current, Labrador Sea Water, variability, transport, potential vorticity

1. Introduction

2 In the traditional view of the North Atlantic Deep Water (NADW) circu3 lation, the Deep Western Boundary Current (DWBC) was considered to be 4 the main pathway from the high-latitude water mass formation regions into 5 the subtropical domain. The existence of the DWBC was first predicted by 6 Stommel (1958) who invoked a deep boundary current to close the abyssal 7 circulation. But it was not until 1960 that the DWBC was observed for the 8 first time (Swallow and Worthington (1961)). At intermediate depths the 9 North Atlantic's DWBC is occupied by Labrador Sea Water (LSW). This water mass is believed to originate in the Labrador and Irminger Seas as well as in the Labrador current (Pickart et al. (1997)). Modeling studies suggest that changes in the Meridional Overturning Circulation (MOC) are related to the rate of production of LSW (e.g. Mauritzen and Häkkinen (1999), 
Bailey et al. (2005), Böning et al. (2006)).

The time-averaged DWBC at mid-latitudes in the North Atlantic appears as a well-organized current with little vertical shear and typical velocities of 5 to $10 \mathrm{~cm} / \mathrm{s}$ (Joyce et al. (2005) and Toole et al. (2011)). Looking closer, observations at the exit of the subpolar gyre (e.g. Schott et al. (2004), Schott et al. (2006) and Pickart and Smethie (1998)), reveal that the DWBC has two separated velocity cores, a shallow one between 500 and 2000m, and a deeper one centered around $3000 \mathrm{~m}$. About $40^{\circ} \mathrm{N}$, the steepness of the continental slope and the relative position of the Gulf Stream, cause the two cores to appear aligned and the overall flow in the DWBC to look more barotropic.

The upper part of the water column above the DWBC, extending from the surface to the upper limit of the LSW is typically referred to as Slope Water (SW) and represents a mixture of very fresh and cold shelf water originating in the Subpolar North Atlantic that is transported into the subtropics by the Labrador Current, and waters from the Northern Recirculation Gyre (NRG) of the Gulf Stream. The mean flow in this upper part of the water column has very similar speeds to those found in the DWBC underneath it (Flagg et al. (2006)). Underneath the Slope Water, the uppermost layer of the DWBC, extending from 500m to $1000 \mathrm{~m}$ approximately, is occupied by upper Labrador Sea Water (uLSW). uLSW may be formed by convection near the boundary in the Labrador Sea (Pickart et al. (1997)) or in the middle of the basin during less severe winters (Stramma et al. (2004), Yashayaev (2007), Kieke et al. (2006) and Kieke et al. (2007)). Because convection down to the level of uLSW can occur under moderate winter conditions, this water mass is thought to be renewed every year (Pickart et al. (1997)) unlike 
its deeper counterpart, the deep Labrador Sea Water (dLSW). The dLSW occupies the intermediate depths of the DWBC, typically from 1000m down to $2500 \mathrm{~m}$. dLSW is a thicker layer of much more homogeneous fluid, since it is formed in the middle of the Labrador Basin during winters when favorable conditions for deep convection (as deep as 2000m or more) occur. The densest component of the NADW within DWBC below the dLSW, typically referred to as Overflow Water (OW), is formed in the Nordic Seas and their adjoining sill overflows (e.g. Worthington (1976) and Pickart (1992)).

After they are formed both types of LSW move into regions where the local stratification demands their depth to increase in order to conserve density. Once no longer in contact with the atmosphere their potential vorticity (PV) tends to be conserved (in the absence of mixing). It is this insulation from surface forcing and the low PV values that characterize water of convective origin, that allow LSW to be traced by its PV minimum. Based on maps of the North Atlantic PV, Talley and McCartney (1982) identified three main pathways for the newly-formed LSW: (1) northeastward into the Irminger Sea, (2) southeastward underneath the North Atlantic Current and (3) southward via the DWBC. Similar results were found by Rhein et al. (2002) based on chlorofluorocarbon (CFC) distribution and by Bower et al. (2009) from float observations (though by only a few of their floats).

Along the east coast of the US between Grand Banks and Cape Hatteras, due to conservation of potential vorticity, the steep bathymetry acts to constrain the path of the DWBC to lie within one hundred kilometers of its mean position over the continental slope. For that reason it is relatively straightforward to monitor the DWBC transport here as compared to 
$26.5^{\circ} \mathrm{N}$, where the DWBC sits above a relatively flat bottom and exhibits large offshore shifts (Bryden et al. (2005)).

Estimates of the mean DWBC transport in the North Atlantic suggest the mean DWBC exhibits some variation along its path. East of the Grand Banks, Schott et al. (2006) estimated that the mean transport of the DWBC below the $\sigma_{\theta}=27.68 \mathrm{~kg} / \mathrm{m}^{3}$ (upper boundary of the uLSW) was $-17.5 \pm$ 6.8Sv. As the NADW enters the subtropical domain, at $55^{\circ} \mathrm{W}$, Pickart and Smethie (1998) obtained a slightly larger mean transport of $-18.9 \pm 6.3 \mathrm{~Sv}$ for the same water masses. Further downstream at $70^{\circ} \mathrm{W}$, Joyce et al. (2005) reports an Eulerian mean of $-16.5 \pm 2.5 \mathrm{~Sv}$, similar (within the error bars) to the more recent estimates by Toole et al. (2011) from 4 years of moored velocity measurements at the same site $(-18 \mathrm{~Sv}$ 4-layer Eulerian mean, $-25.1 \mathrm{~Sv}$ when averaged in stream coordinates). On approach to Cape Hatteras, most of the DWBC waters in the upper part of the water column, including some within the LSW depth range, are entrained by the Gulf Stream and recirculate back into the mid-Atlantic Bight. Only the deepest components manage to cross directly under the Gulf Stream (Bower and Hunt (2000) and Pickart and Smethie (1993)). South of the cross-over, the DWBC recovers some of the lost transport via recirculation, and by $26.5^{\circ} \mathrm{N}$ the mean transport is increased in magnitude to -35 to $-40 \mathrm{~Sv}$, half of which appear to be locally recirculating waters (Lee et al. (1996) and Bryden et al. (2005)).

Our knowledge of the temporal variability of the DWBC transport is much less complete due to the lack of long term measurements. The available records show that the DWBC velocity field is highly variable on intraseasonal scales, and it is only the density field that shows clear interannual variations 
(Schott et al. (2006) and Vaughan and Molinari (1997)).

Observational studies suggest that the fraction of the LSW exported via the DWBC may not be as large as once believed. Fischer and Schott (2002) found that none of the profiling floats deployed in the Labrador Sea in the Spring and Summer of 1997 were able to navigate the rough topographic features around Flemish Cap and enter the subtropical domain. Instead, all of their floats recirculated back into the Labrador Sea, or flowed eastward toward the Charlie Gibbs Fracture Zone. However, Getzlaff et al. (2006) modeling study showed that the profiling nature of these floats had a significant impact in the float trajectories. They found that shorter surface time resulted in more floats following the DWBC path. In a more recent study, Bower et al. (2009) deployed a number of RAFOS floats (non-profiling) in the period 2003-2006 at the LSW depth within the Labrador Current and obtained similar results to those by Fischer and Schott (2002). Only 8\% (3 out of 40) of the floats deployed in LSW depth range north of the Grand Banks followed the classic path along the continental slope to subtropical latitudes. Most of the floats recirculated back into the Subpolar North Atlantic. Among these that eventually traveled south, most did via an interior pathway. It is important to mention that neither Fischer and Schott (2002) profiling floats nor Bower et al. (2009) floats (isobaric) were following density surfaces. This could in part explain some of the differences between these float-derived pathways and Kieke et al. (2009) findings. Based on the spreading of $\mathrm{T} / \mathrm{S}$ anomalies observed in hydrographic data, as well as mooring and ARGO floats, they concluded that the DWBC is the main pathway for the export of the LSW. In addition, both these float studies mentioned 
above took place during weak to no-convection conditions in the Labrador Sea (Yashayaev (2007)); it is possible that LSW pathways are different during years of strong convection.

In this study we use data from a series of Moored Profiler mooring deployments in the DWBC downstream from the Grand Banks to characterize the variability at this site and investigate changes in the NADW, with particular focus on the LSW. We will relate the observed changes to changes in dense water formation in the subpolar North Atlantic. The paper is organized as follows: first we introduce the data set. A description of the time-averaged and anomaly fields measured by Moored Profilers, and the patterns of covariability between the density and velocity fields follows. Next we explore the variability in the depth-integrated velocity seen at the mooring site and discuss what the possible sources of this variability are. And then before the discussion, we describe the observed changes in the water masses and relate the variability to the spreading rates for these water masses away from their formation regions.

\section{The dataset: W3 deployment.}

The bulk of the data used in this study were obtained from a series of 61 year-long subsurface mooring deployments at a site located on the continental slope southeast of Cape Cod near the $3000 \mathrm{~m}$ isobath at approximately $39^{\circ} \mathrm{N}$ $69^{\circ} \mathrm{W}$ (hereafter $\mathrm{W} 3$, see figure 1 ). The moorings were equipped with a McLane Moored Profiler (MMP) that measures conductivity, temperature, pressure and horizontal velocity, and well as Vector Averaging Current Meters (VACM) and MicroCAT's fixed at the top and bottom of the mooring. The 


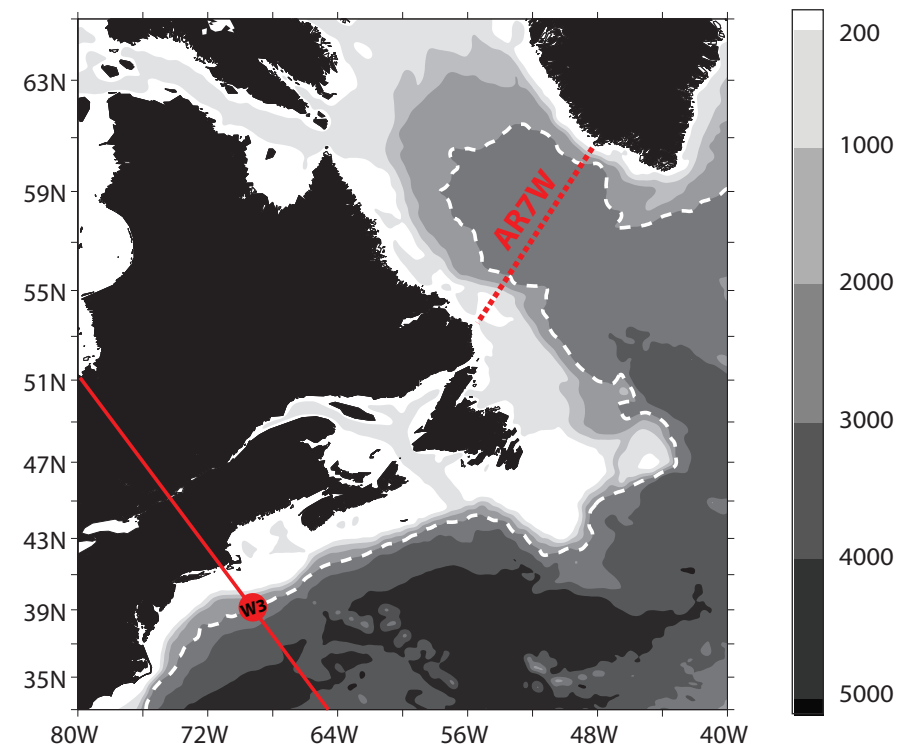

Figure 1: Map (bathymetry in meters) of the area of study. The red circle indicates the location of mooring W3. WOCE line AR7W in the Labrador Sea (used in Yashayaev (2007)) is shown by the dashed red line. The solid red line is T/P-Jason altimeter track 126 , coincident with Line $\mathrm{W}$. The dashed white line tracks the $3000 \mathrm{~m}$ isobath from the Labrador Sea into the western North Atlantic.

record examined here consists of one deployment in 2001-2002 that returned profile data from November 2001 to August 2002, and 5 sequential oneyear deployments (from April 2003 to May 2008). During 2004-2008, W3 was deployed together with 4 other moorings as part of the Line $\mathrm{W}$ program (http://www.whoi.edu/science/PO/linew/index.htm) in an effort to monitor the transport of the DWBC in the western North Atlantic. Results from the first 4 years of the full array deployment are presented by Toole et al. (2011) and Pena-Molino (2010).

After processing (for details on the processing see Toole et al. (2011)), the MMP data set consists of 2dbar vertical resolution profiles of temperature, 
salinity and absolute horizontal velocity data. The MMP's were programmed to sample in bursts, with a burst typically consisting of 4 profiles spaced 9 hours apart, and bursts separated by 5 days. In order to filter tidal and inertial motions, all profiles within a burst were averaged (Silverthorne and Toole (2009)), thus the final temporal resolution examined here is given by the frequency of the bursts rather than that of the individual profiles. These and other details for each deployment are shown in Table 1. One of the most valuable attributes of the MMP data is its vertical resolution, allowing us to accurately compute planetary potential vorticity (PPV, defined here as $\left.\left(-f / \rho_{0}\right) \partial \rho / \partial z\right)$, a key variable in the study of water masses of convective origin. An important limitation of the dataset is missing data. In the presence of strong currents the MMPs sporadically returned incomplete profiles or failed to profile as scheduled, and often exhausted their battery supply a month or so before each mooring was serviced.

Table 1: W3 mooring deployments.

\begin{tabular}{lll}
\hline \hline Time & MMP depth range & Burst scheme \\
\hline $11 / 2001-08 / 2002$ & $94-2960 \mathrm{~m}$ & 4-profiles, 4-day \\
$05 / 2003-04 / 2004$ & $74-2950 \mathrm{~m}$ & 4-profiles, 5-day \\
$04 / 2004-05 / 2005$ & $60-3150 \mathrm{~m}$ & 4-profiles, 5-day \\
$05 / 2005-04 / 2006$ & $104-3220 \mathrm{~m}$ & 4-profiles, 7.5-day \\
$04 / 2006-04 / 2007$ & $60-3192 \mathrm{~m}$ & 4-profiles, 5-day \\
$04 / 2007-05 / 2008$ & $60-3190 \mathrm{~m}$ & 6-profiles, 5-day \\
\hline
\end{tabular}

Some additional processing was performed on the data before the present 
analysis. Missing data were treated as follows: in the vertical, incomplete profiles that were missing more than $30 \%$ of the profile span (normally at the top and/or bottom of the mooring), were excluded from this analysis. For the remaining partial profiles, VACM and MicroCAT data ${ }^{1}$ were used to fill in the gaps using linear interpolation. Small temporal gaps (smaller than 14 days) were also filled by linear interpolation; larger gaps were masked. The resulting data were then gridded onto a 7-day common time axis, and only the depth range sampled by all 6 mooring $(220-2900 \mathrm{~m})$ deployments was retained.

One last step in the post-processing involved identifying and excluding Warm Core Ring (WCR) events. W3 is located north of the mean axis of the Gulf Stream but close enough that large Gulf Stream excursions (rings and meanders) can sometimes block and reverse the otherwise equatorward DWBC flow at W3. These excursions represent a significant fraction of the variability in the region and have a large impact on the record-mean temperature and salinity. Defining anomalies relative to the full-record mean, including the rings, produces temperature and salinity anomaly fields that consist of positive anomalies (warm and saline) when the rings are present, and negative anomalies (cold and fresh) during ring-free periods. It was therefore necessary to exclude the rings to isolate the internal variability of the water masses that constitute the NADW beyond the effects of the rings. Because the large horizontal velocities associated with the rings often pre-

${ }^{1}$ VACM and MicroCAT for the four more recent deployments, those that were part of the full Line $\mathrm{W}$ array, were obtained at approximately $1 \mathrm{~m}$ from the top and bottom of the MMP depth range. 
vented or limited the ability of the MMPs to profile, ring periods were largely already eliminated from the data set. In those cases when an MMP was able to profile during all or part of a ring event, the data from those periods were manually eliminated. To determine when a set of profiles was contaminated by a ring, we took advantage of the large temperature anomalies associated with warm core rings, and eliminated profiles (from the already gridded data) that contained temperature anomalies (relative to the full record mean profile rings included) in the upper $1000 \mathrm{~m}$ with amplitudes three times (or more) larger than the standard deviation of the time series. The exclusion of rings as described above implied an $8 \%$ reduction in the record's length.

\section{Results}

\subsection{Evolution of the hydrographic properties and circulation at W3}

3.1.1. The time-averaged and the anomaly fields.

Temperature, salinity, PPV and downstream velocity ${ }^{2}$ anomalies in depth space were obtained by removing the record mean profiles after rings were excluded (right panels figure 2). The anomaly fields were subsequently normalized by the standard deviation at each depth level to account for the larger variances observed in the upper ocean relative to the abyss (left panels figure 2 ). Results presented here do not change qualitatively if the normalization is not performed.

The time-averaged density field at W3 is typical for the Slope Water region in the western North Atlantic with a relatively shallow pycnocline

\footnotetext{
${ }^{2}$ Rotated into the along-isobath direction, ca. $29^{\circ}$ counterclockwise from the east. Positive velocities are to the northeast, and negative to the southwest.
} 

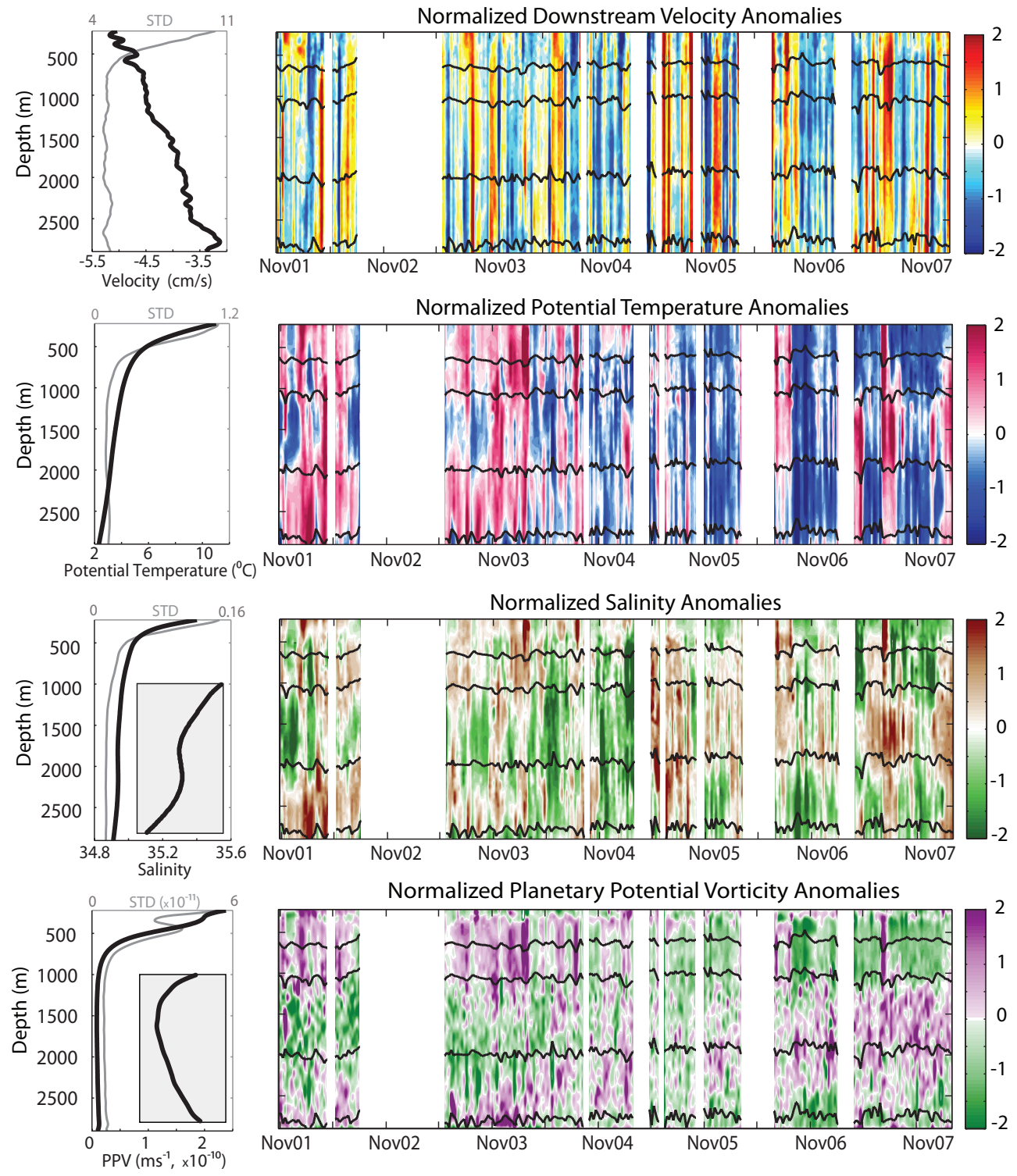

Figure 2: The color maps on the right show normalized time series of, from top to bottom, downstream velocity, potential temperature, salinity and planetary potential vorticity (PPV) anomalies at W3 (depth axis beginning at 150m). Neutral density surfaces bounding the water masses uLSW, dLSW and OW (table 2) are in black. Left panels show the mean, thick black line (bottom axis), and standard deviation (STD), thin gray line (top axis), profiles for the corresponding variables. A blow-up of the bottom $2000 \mathrm{~m}$ of mean PPV and salinity profiles are shown in the shaded box to resolve the PPV and salinity minima in the dLSW layer. 
compared to the stratification just a few hundred $\mathrm{km}$ further offshore south of the Gulf Stream, and a PPV and salinity minima at mid depth indicative of the presence of LSW. At 220m depth, mean temperature values are around $10^{\circ} \mathrm{C}$ (waters to the north of the Gulf Stream are typically around $12-13^{\circ} \mathrm{C}$ at $150 \mathrm{~m}$ ) bounded below by a steep thermocline followed by a gradual temperature decrease all the way to the bottom, where potential temperatures of about $2^{\circ} \mathrm{C}$ are found. Mean salinity values range from 35.4 at $220 \mathrm{~m}$ to 35 at the base of the thermocline. Below the thermocline, salinity changes are much smaller, with a local minimum at the LSW layer, co-located with a PPV minimum. The mean velocity is to the southwest at all depths, with maximum velocities of $-5 \mathrm{~cm} / \mathrm{s}$ in the top $500 \mathrm{~m}$ and a nearly linear vertical shear that brings the record mean velocity down to $-3.5 \mathrm{~cm} / \mathrm{s}$ below $2500 \mathrm{~m}$. The variability in the temperature and salinity fields is characterized by a change in the sign of the anomalies from the first to the second half of the record. This character change is clear in the normalized temperature anomalies, with the first half of the record being on average warmer than the later half, but rather small in the salinity anomalies. The vertically averaged salinity anomalies in the second half of the record are fresher by 0.003 (calculated reversing the normalization) than those in the first half. These warm (cold) and saline (fresh) anomalies don't always occupy the entire water column, but rather have a vertical structure consisting of alternating layers of warm (and saline) and cold (and fresh) water roughly contained within the depth range of the SW, uLSW, dLSW and OW (see figure 2). Anomalies in the SW, uLSW and OW vary in phase, with warm and saline anomalies for most of the period 2001-2003 and cold and fresh anomalies from 2006 until the 
end of the record. Anomalies in the dLSW depth range vary with opposite sign. In the transition period between 2004 to 2006, as well as in early 2002, the anomaly fields appear nearly depth independent.

Changes in the temperature and salinity fields are only partially compensated. Fluctuations in the density field, as is typical in this region, are dominated by temperature changes. Thus associated with the relative cooling from the early part of the record to the later, the water column contracts and the density increases. When the density field is vertically integrated to estimate dynamic height, we find that these uncompensated $\mathrm{T} / \mathrm{S}$ changes lead to an overall drop of the free surface ${ }^{3}$ of about $10 \mathrm{~cm}$. This drop in the free surface is in good agreement with changes in Sea Surface Height (SSH) measured by Topex/Poseidon and Jason altimeters. The difference between the averaged SSH for the same two 6-month periods used in the mooring calculation corresponds to a drop in $\mathrm{SSH}$ of $8 \mathrm{~cm}$.

The most interesting of the signals are found in the PPV field. There is a clear change in the vertical structure of the PPV around 2004. The first half of the record is characterized by a thick layer of relatively low PPV at the level of the dLSW and a more stratified uLSW layer. In the second half, the situation reverses. The PPV minimum gradually migrates upwards to occupy the whole range of uLSW and the part of the water column right above it (SW). The stratification in the dLSW increases during this time. The timing of this transition from a denser type of LSW to a lighter ver-

\footnotetext{
${ }^{3}$ Calculated as the final free surface, given by the average over the last 6 months of the record, minus the initial free surface, given by the average of the first 6 months of the record.
} 
sion is consistent with the evolution of the LSW observed in the Labrador Sea about a decade earlier. Stramma et al. (2004) found from a series of hydrographic observations taken between 1996 and 2001, that after the exceptionally deep convection in the central Labrador Sea ceased in the mid 1990's, the dLSW layer became thinner, while the uLSW layer, almost absent before 1996, increased its thickness up to 2001. The same transition from the denser to the lighter LSW observed here at $69^{\circ} \mathrm{W}$ around 2004 was observed in the central Labrador Sea in 1998 (Yashayaev (2007)). This implies an averaged water parcel transit time from the Labrador Sea (from WOCE line AR7W in figure 1) to W3 of 6 years, equivalent to a speed of $2.5 \mathrm{~cm} / \mathrm{s}$ following the $3000 \mathrm{~m}$ isobath. Similar spreading rates were found by Fine et al. (2002) from CFC concentrations along the DWBC.

\subsubsection{Vertical modes of co-variability.}

To examine the joint variability in the downstream velocity, potential temperature, salinity and planetary potential vorticity fields we performed a multivariate EOF decomposition. Due to the different nature of the variability in the velocity signal, more rapidly fluctuating compared to the other variables, standard EOF analysis did not produce a robust, physically-meaningful leading mode. The first and second modes resulting from this analysis (not shown here) were mixed. The mixing of modes had very little effect on the hydrographic variables (temperature, salinity and PV), since they are strongly correlated, and EOF analysis can therefore easily isolate the covarying part in them in the form of orthogonal modes with exponentially decreasing amplitude. The first and second velocity modes, on the other hand, had similar amplitudes (both large) and opposite sign that tended to 
cancel each other out when the modes were combined, typical of modes that are poorly separated. In order to extract the part of the velocity variability that covaried with the temperature, salinity and PPV fields, we performed a VARIMAX-rotation on the first three $\operatorname{modes}^{4}$ (von Storch and Zwiers (1999)). The rotation significantly changed the structure, both amplitude and sign, of the leading velocity mode while the temperature, salinity and PPV spatial patterns remained practically unchanged. This being again a consequence of the already well-separated nature of the hydrographic variables (highly correlated). An alternative way of extracting the part of the velocity field that is correlated with the temperature, salinity and PPV fields, is by calculating the joint EOF of the hydrographic fields alone, and then computing correlation indices between the resulting leading principal component, and the velocity time series at each depth. The correlation indices (one for each depth level) obtained by this method reproduce the exact same velocity (spatial) pattern that is obtained via VARIMAX rotation, thus justify the use of rotation and our final choice of leading mode. This mode is described next.

The leading rotated mode (figure 3 ) is characterized by cooler and fresher water at all depths, with slightly smaller amplitude at mid depth, in particular at $1500 \mathrm{~m}$ for temperature and $2000 \mathrm{~m}$ for salinity. In PPV, the mode consists of alternating layers of low-high-low anomalies in depth with interfaces (zero-crossings) at 1500 and $2500 \mathrm{~m}$. The velocity mode is characterized by negative velocities (stronger southwestward flow) down to $2500 \mathrm{~m}$, with little vertical shear, and a sign reversal in the bottom 500m (in-phase with posi-

\footnotetext{
${ }^{4}$ One disadvantage of the rotation is the loss of information regarding the amount of variance explained by each of the rotated modes (see von Storch and Zwiers (1999).
} 
tive PPV anomalies at mid-depth). The principal component of the leading mode, PC1, is dominated by a sign change at the beginning of 2004 going from a mostly negative (warmer/saline) early part of the record to a mostly positive (colder/fresh) in the second half. This relationship between the temperature and velocity fields captured by the leading EOF, stronger velocities to the southwest in phase with colder water, can be also reconciled with the drop in the surface elevation discussed in the previous section. If the surface elevation inshore from W3 remains unchanged or experiences a smaller drop, a plausible scenario since shelf and slope are governed by different processes, the slope of the free surface would have increased causing a stronger velocity to the southwest as captured by the EOF.

While the PPV mode clearly captures the vertical structure of positive and negative anomalies discussed earlier, the temperature and salinity modes fail to do so. The amplitude of the mode at intermediate depths decreases, but the mode is single signed in depth. These depth-independent temperature and salinity changes could be caused by changes in the rate of entrainment of warm and saline Gulf Stream waters as the LSW progresses southward, or due to the effect of isopycnal heaving in the depth-averaging process. These processes are then emphasized by the EOF's tendency to select the normal modes of the system ( $n^{\text {th }}$-mode having $(n-1)$ zero-crossings) (North (1984)).

The amplitude of the rotated velocity mode, once the normalization is undone, is one order of magnitude smaller than the standard deviation of the full velocity fluctuations. Considering the mean downstream velocity profile $(-3.5$ to $-5 \mathrm{~cm} / \mathrm{s})$ the fluctuations that are captured by this mode represent 

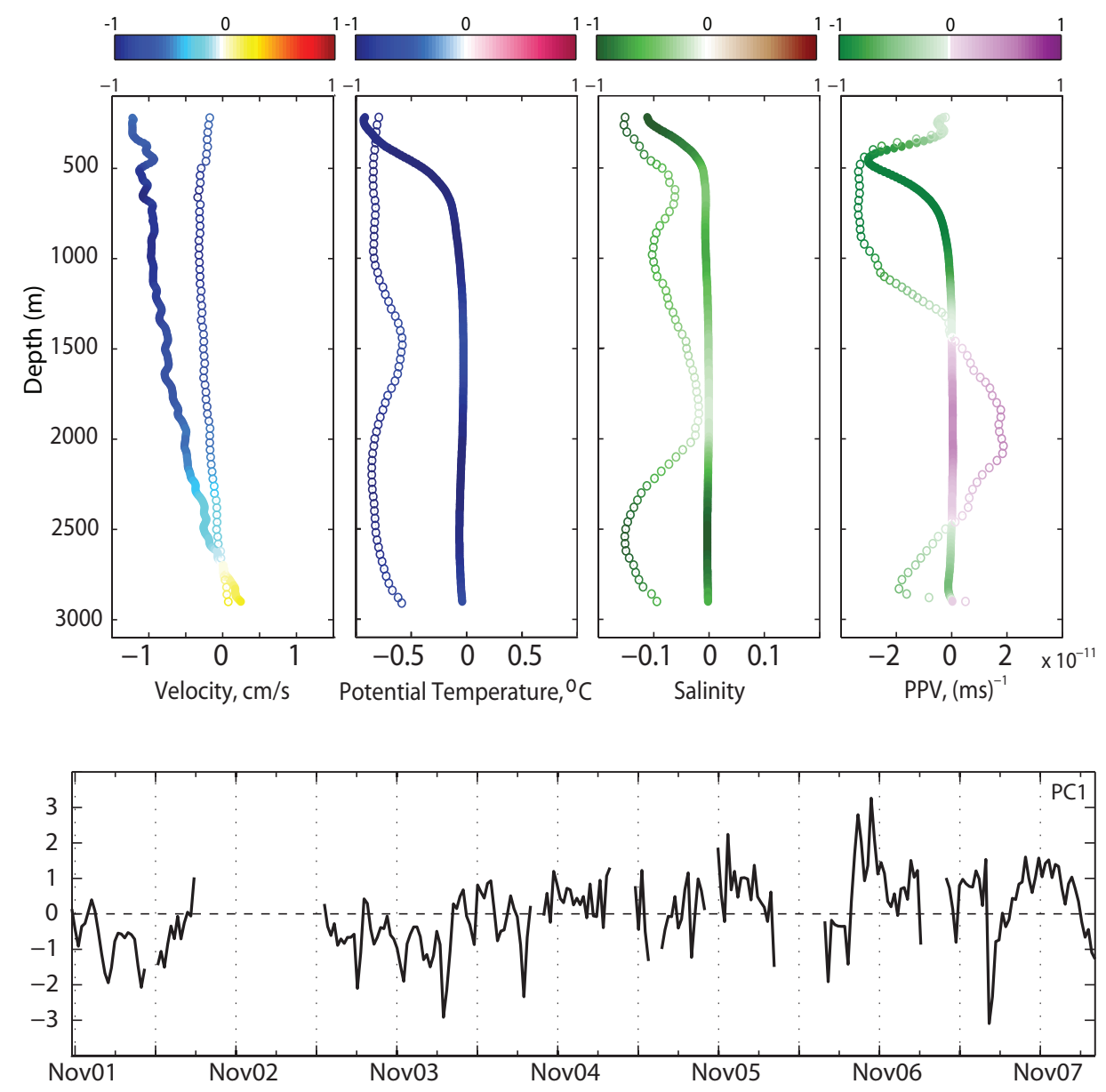

Figure 3: Top panels show the leading mode of the VARIMAX-rotated EOF of the downstream velocity, potential temperature, salinity and PPV. Open circles show the normalized values (top axis), and solid circles show absolute values (bottom axis, once the normalization is reversed). The color scale represent the amplitude of the normalized values, therefore ranging from -1 to 1 . The amplitude and sign of the patterns captured by these EOFs change over time according to their corresponding principal components, shown in the bottom panel. 
approximately $25 \%$ of the mean flow's amplitude. This implies that if we add or subtract the rotated velocity mode times one standard deviation of the principal component, the mean velocity profile will accelerate or slow down by $1 \mathrm{~cm} / \mathrm{s}$ (see figure 4 ). When the mode is subtracted from the mean, the strength of the flow (southwestward) in the upper $2000 \mathrm{~m}$ decreases, while it increases in the bottom $500 \mathrm{~m}$. This results in an overall reduction of the shear. The opposite is true when the mode is added to the mean. When the mode reaches its maximum amplitude $(\mathrm{PC} 1 \approx 2)$, the velocity anomaly is still only $50 \%$ of the amplitude of the mean flow, which is not large enough to cause flow reversals.

Based on the VARIMAX-rotated leading EOF, only some $10 \%$ of the variability in the flow is related to changes in the density field captured by PPV mode 1 . The dominant mode of variability of the velocity alone (capturing approximately $45 \%$ of the variance), $E O F_{V}$, is also shown in figure 4. When the amplitude of this mode is multiplied by the standard deviation of the corresponding PC1 (not shown here), $P C 1_{V}$, is comparable to the amplitude of the mean. Subtracting this mode from the mean can produce a flow reversal in the deeper part of the water column where the mean flow is weaker. At times when $P C 1_{V}$ is large (twice the standard deviation), this mode can reverse the flow in the entire water column. $P C 1_{V}$ fluctuates at higher frequencies than does the joint mode. Some of these fluctuations are related to changes in the direction of the flow, not in its strength. The departures of the direction of the instantaneous flow from the downstream direction are rather large. Only when the velocity is averaged over periods longer than 6 months does the direction of the flow start to converge to 


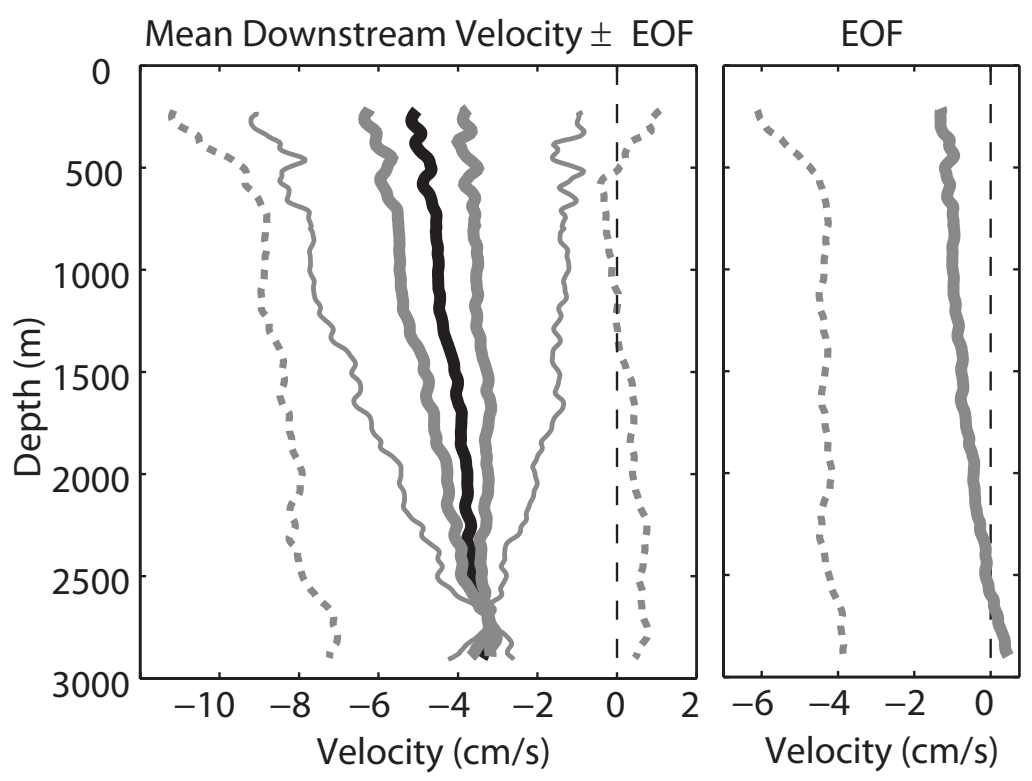

Figure 4: The right panel represents the re-scaled (full velocity units) downstream velocity leading EOF (VARIMAX-rotated), in solid gray, and for the velocity alone, dashed gray. In the left panel the mean downstream velocity is shown in black, the mean $\pm E O F_{V}$ in dashed gray, and the mean \pm the rotated mode and \pm the maximum value in $\mathrm{PC} 1$ times the rotated mode, in thick and thin gray lines respectively. At $2800 \mathrm{~m}$, the combined rotated mode has zero amplitude and so the four combinations of mean plus mode converge to the mean value. 
that of the mean. Year-to-year differences in the annually-averaged flow are comparable in amplitude to the variability captured by the joint EOF. So we can think of the joint EOF as a filter that is selecting only the fluctuations that represent the low-frequency changes in the strength of the flow and not in its direction.

In the deeper part of the water column, some of the high frequency variability associated with directional changes is due to Topographic Rossby Waves (TRW). Their presence in this area is well documented in the literature (e.g. Thompson and Luyten (1976), Pickart and Watts (1990), Pickart (1994) and Fratantoni and Pickart (2003)). TRW's are bottom intensified with periods at Line $\mathrm{W}$ ranging from 25-40 days. In the upper 1000m, most of the observed directional changes are related to Gulf Stream rings and meanders, also very frequent at this location (eg. Brown et al. (1986) and Watts and Johns (1982)). Although most of the rings and meanders were excluded from the record by eliminating extreme warm and salty events, part of their signal still remains. In velocity, the amplitude of this signal is large compared to the much weaker DWBC variability, and therefore picked up by the EOF analysis as one of the dominants modes.

\subsection{The transport response to changes in the $L S W$}

One of the interesting results from the EOF analysis was the in-phase/outof-phase relationship between the velocity and the PPV for the uLSW and dLSW. While the PPV anomalies in the upper and deep LSW had opposite sign, the sign of the corresponding velocity anomalies was the same. Considering the temporal pattern of the mode, PC1, we found that when the flow was strong to the southwest, the cold, fresh, and low PPV anomalies were 
located in the uLSW depth range. When the colder, fresher low PPV water was found in the dLSW depth range, the velocity anomalies were positive and thus the southwestward flow was weaker. How does this relation translate into transport? The transport per unit width, $T$, for the uLSW and dLSW layers can be expressed as the product of the layer thickness, $h$, and the velocity averaged within each layer, $v$ :

$$
T=v \cdot h
$$

Both layer thickness and velocity may be separated into a mean (overbar) and a perturbation (prime):

$$
v=\left(v^{\prime}+\bar{v}\right)
$$

$$
h=\left(h^{\prime}+\bar{h}\right)
$$

Substituting into the transport expression and subtracting the mean, we find the variability in the transport, $T^{\prime}$, consists of three terms:

$$
T^{\prime}=(v \cdot h)^{\prime}=v^{\prime} \cdot \bar{h}+\bar{v} \cdot h^{\prime}+v^{\prime} \cdot h^{\prime}
$$

The first term in the right hand side of the equation represents changes in the transport due to the changes in the velocity, the second includes changes due to changing layer thickness, and the last is the non-linear term representing the part of the transport variability that is due to correlated changes in the velocity and layer thickness. Because we are interested in the low frequency signals that are associated with changes in the density field, we replace $v^{\prime}$ by the part that is captured in the EOF analysis of the previous section. Using the neutral density boundaries for the water masses shown in Table 2, we calculated the transports time series for the uLSW and dLSW (figure 5). 


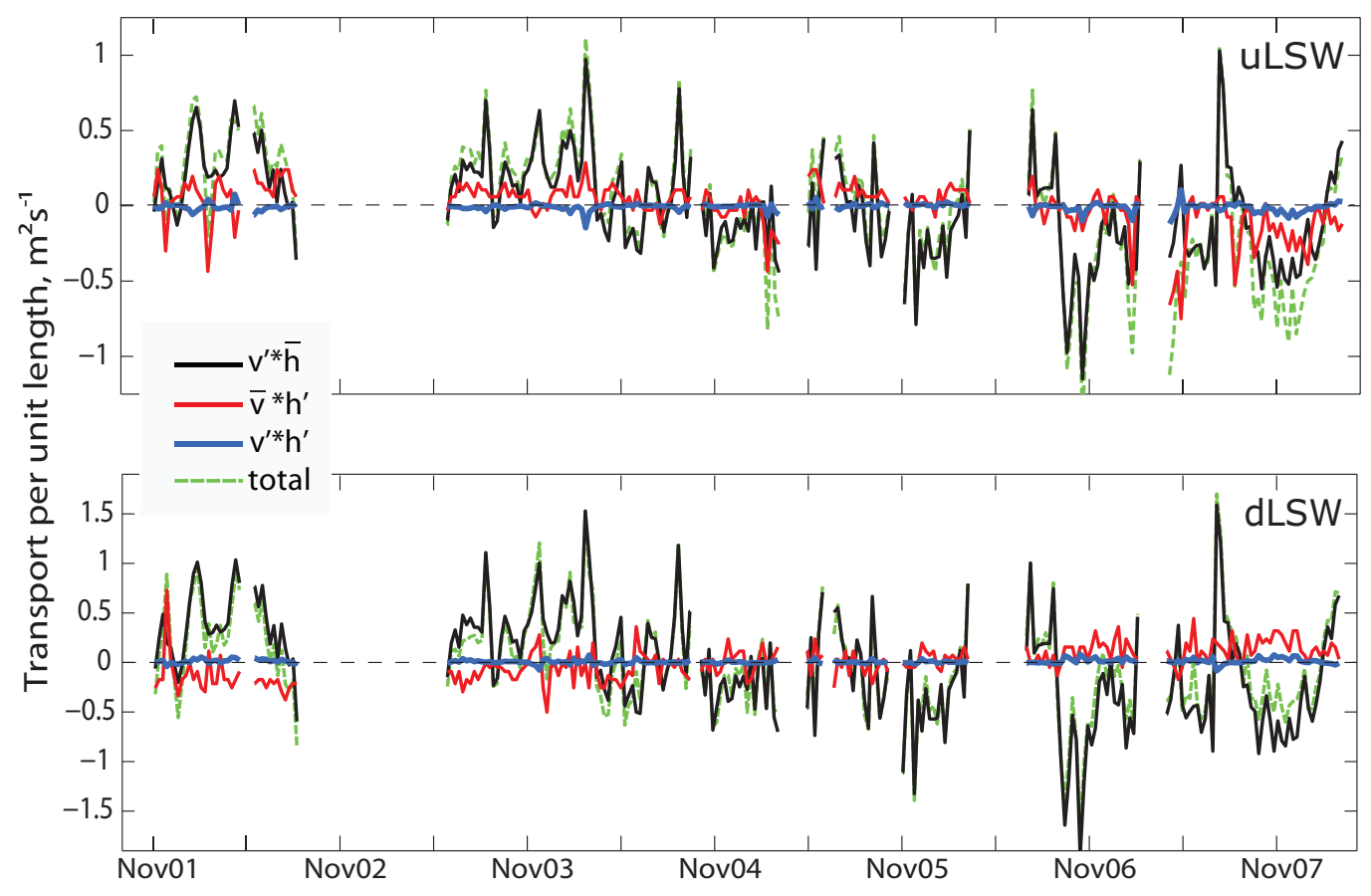

Figure 5: Transport decomposition. uLSW shown in the upper panel and dLSW in the lower (different vertical scales). Values are transport per unit length, $m^{2} s^{-1}$. Negative meaning downstream in the direction of DWBC (southwestward). 
Table 2: Neutral density surfaces, $\gamma_{n}$, used in defining the water mass boundaries. Values shown in $\mathrm{kg} / \mathrm{m}^{3}$.

\begin{tabular}{ccc}
\hline \hline & UpperBoundary & LowerBoundary \\
\hline uLSW & 27.8 & 27.897 \\
dLSW & 27.897 & 27.983 \\
OW & 27.983 & 28.066 \\
\hline
\end{tabular}

The contribution from the non-linear term to the transport is negligible, although of opposite sign for the two water masses. Variations in the transport are, for the most part, due to variations in the velocity field. This is in large part due to the fact that $\bar{h}>>h^{\prime}$ and $\bar{v} \approx v^{\prime}$. The evolution of the total transport for both layers is similar, with increasing southward transports toward the end of the record. The distribution between the terms is different. In the uLSW, the contribution of layer thickness and velocity have the same sign, they are both positive or both negative, while in the dLSW these two terms are opposing. When the southward dLSW flow accelerates, the layer thickness decreases. Based on the term $\bar{v} \cdot h^{\prime}$ alone, we see some degree of compensation between the transport of the two LSW types, as found by Rhein et al. (2007) in the Labrador Sea. But this compensation at W3 is done entirely by the density field. When the uLSW layer expands the dLSW contracts. The amplitudes of the trends are similar, and they largely cancel out when added together. This compensation is, as we said, partial because transport changes are due to both changes in the layer thickness and changes in the velocity field. Thus, changing thickness of opposite sign in the two 
classes of LSW can still be associated with a net transport change of the same sign (dashed line in figure 5) caused by velocity changes.

\subsection{Water mass variability}

Some of the variability observed in figure 2 is related to the effect of the heaving of the isopycnals on the depth-averaging, rather than to real changes in the water mass. To separate these two sources of stratification variability and investigate changes in the water mass properties, we transformed the vertical coordinate to neutral density. Using the mean density profile as a reference, we defined the increments in the density axis, $\gamma_{n}^{i}$, to be volume conserving on average. In one dimension, this is equivalent to saying that the mean vertical distance between all adjacent density surfaces is the same, $\delta Z_{\gamma_{n}^{i}}=$ constant, not the density interval itself, $\delta \gamma_{n}^{i} \neq$ constant

Two aspects of the water mass variability were explored in the isopycnal coordinate system. First, we looked at temperature and salinity changes in a water mass bounded by two neutral density surfaces using the same layer definitions used in the transport calculation (see Table 2). Second, we looked at changes in the density of a particular water mass. The properties of the water masses formed by convection in the Labrador Sea vary on interannual time scales, and they do so not only by changing their temperature and salinity but their volume and density as well (Yashayaev (2007)). To explore these changes in the density of the different water masses we defined them based on their PPV signature. 


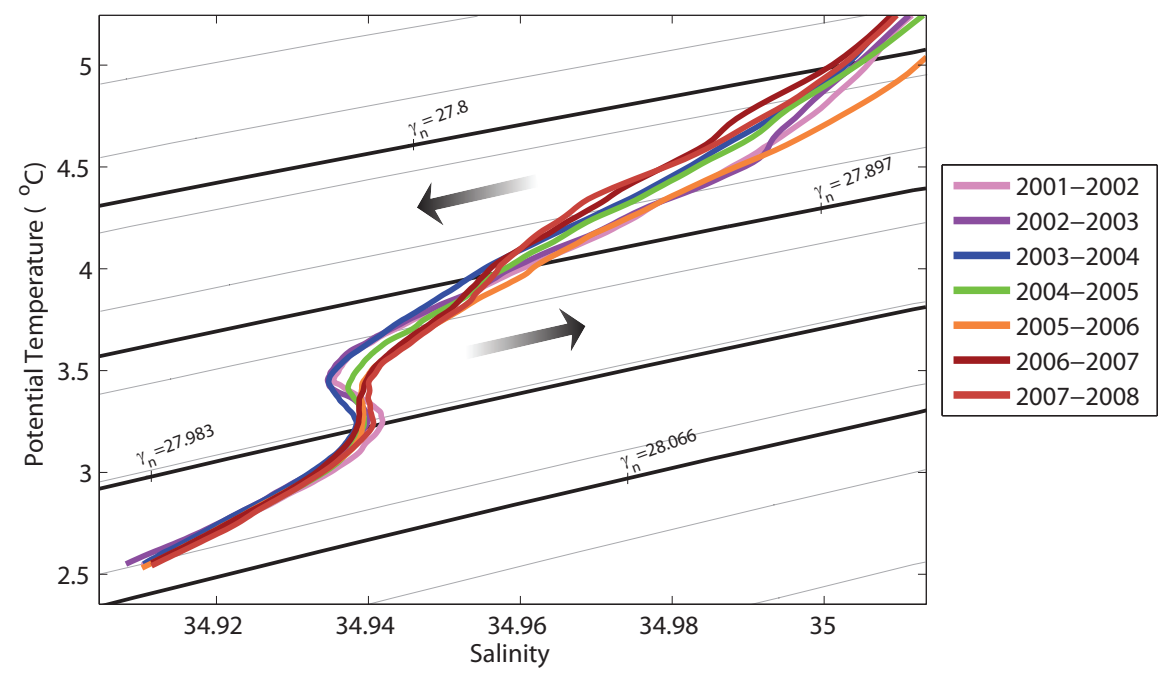

Figure 6: $\theta / \mathrm{S}$ diagram. The gray contours are the isopycnals, in black are the boundaries of the uLSW, dLSW and OW. The arrows indicate the transformation in the dLSW and uLSW layers.

\subsection{1. $\theta / S$ variability (fixed- $\gamma_{n}$ range).}

To explore interannual $\theta / \mathrm{S}$ changes in the water masses the 5.5-year record was binned into November-to-November means (to maximize data usage). The irregular distribution of temporal gaps through the record, in particular the 295-day gap between the first and second deployments, can cause some differences between the annual mean estimates that are not real but the result of averaging different amounts of data. This is also true for the last time interval, which includes only of 6 months of data. We must be careful then in interpreting these results. The only true (unbiased) annual means are those corresponding to years 2003-2007. Means corresponding to the periods 2001-2002, 2002-2003 and 2007-2008 could potentially be biased due to the limited data available (8, 7 and 6 months respectively). 
The $\theta / \mathrm{S}$ diagram of the annually averaged data (figure 6 ) showed that within the dLSW layer, the water became progressively warmer (by about $0.2^{\circ} \mathrm{C}$ ) and saltier (by about 0.01 ) throughout the observational period. The salinity minimum that characterizes dLSW was slightly denser than the mean layer density, suggesting the real boundary of the water mass may be lower than the $\gamma_{n}=27.983 \mathrm{~kg} / \mathrm{m}^{3}$. In time, the minimum eroded and had almost disappeared by the end of the record. The same evolution was seen by Yashayaev (2007) in the central Labrador Sea. In the uLSW the situation was the opposite. The water cooled and became fresher with time. There was no sign of the salinity minimum that characterizes this water mass in the Labrador Sea (Stramma et al. (2004)), presumably due to the mixing with the warmer and more saline surrounding water (Pickart et al. (1996)). The $\theta / \mathrm{S}$ curve for the 2005-2006 period was somewhat anomalous. We believe this is due to a warm core ring event in the Spring 2006, whose effect on the water masses was not completely removed from the record.

\subsubsection{Density variability in the water masses.}

The layer thicknesses of the uLSW and dLSW inferred from the vertical distribution of positive and negative PPV anomalies in figure 2 was more variable than the fixed-density range layer definitions used in the transport calculation. These larger fluctuations in layer thickness were consistent with the evolution of the LSW thickness in the Labrador Sea shown by Yashayaev (2007). The density of the LSW layer that is produced every year by convection is variable as well. These changes are completely missed when the different types of LSW are represented by two fixed density surfaces (e.g. Stramma et al. (2004) and Yashayaev et al. (2007)). For this reason, we 
480

explored density variability within the water masses using PPV to define the layers instead of fixed $\gamma_{n}$ values.

To define the water masses we used a scaled form of potential vorticity in density coordinates, namely potential thickness, in a similar fashion to what is done in Yashayaev (2007). In order to obtain an expression for potential thickness, $\tilde{q}_{\gamma_{n}}$, density is exchanged by pressure in the definition of PPV in Z-coordinates, $q$, and subsequently scaled by pressure:

$$
q \propto-\frac{1}{\rho} \frac{d \rho}{d z}
$$

$$
q_{\gamma_{n}} \propto \frac{d z}{d \gamma_{n}}
$$

Neutral density, $\gamma_{n}$, replaces density, $\rho$, in the isopycnal coordinate system. Because the density coordinate transformation is volume conserving (density intervals are defined so that they contained the same volume of water), $d \gamma_{n}$ in the denominator of the second expression is not constant, thus interpreting $q_{\gamma_{n}}$ can be complicated. For that reason we normalize $q_{\gamma_{n}}$ by $d \gamma_{n}$, and define a new variable:

$$
\tilde{q}_{\gamma_{n}}=q_{\gamma_{n}} \cdot d \gamma_{n}
$$

$\tilde{q}_{\gamma_{n}}$ is a measure of the stretching, in meters, of the density layers (in the infinitesimal sense). In the mean, by definition $\tilde{q}_{\gamma_{n}}=$ constant.

Similar to its Z-coordinate equivalent, due its derivative nature, $\tilde{q}_{\gamma_{n}}$ is very noisy and unless the density field is smoothed, that noise dominates the interannual signals. To avoid this, individual profiles were smoothed with a $250 \mathrm{~m}$ box-car filter, and the top and bottom $150 \mathrm{~m}$ of the water column were eliminated to avoid edge effects. The resulting vertically smoothed profiles were low-pass filtered with 1-year digital Butterworth filter. A one-year filter 


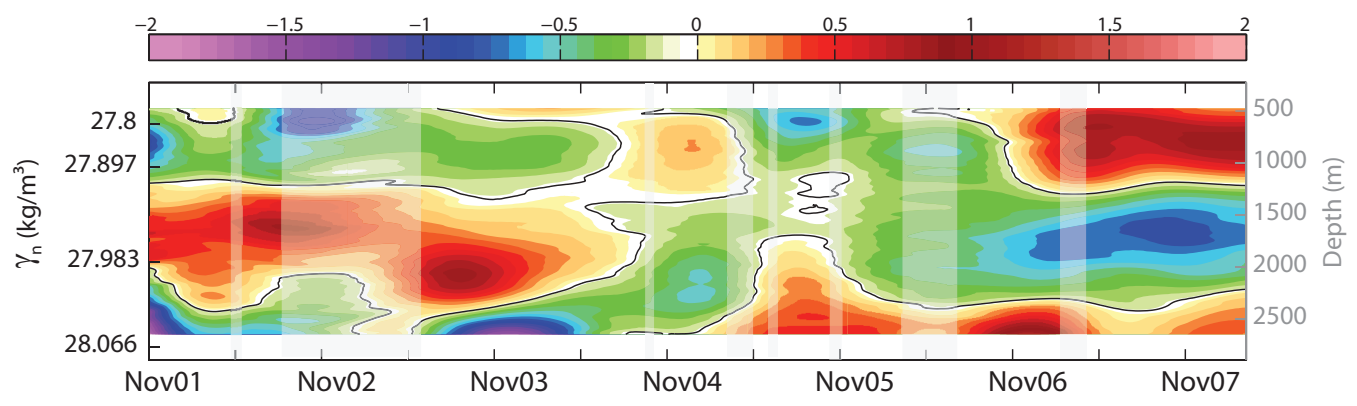

Figure 7: Layer stretching anomaly, $\tilde{q}_{\gamma_{n}}^{\prime}$, in decibars calculated from the smoothed density field. The right axis shows the depth of the corresponding $\gamma_{n}$ in the mean. The black line is the zero anomaly contour, $\tilde{q}_{\gamma_{n}}^{\prime}=0$. The grayded areas correspond to gaps in the original time series.

cutoff was chosen to emphasize the time scale of the fluctuations in the dense water formation process. Gaps in the data were filled by linear interpolation (none of the gaps are longer than the filter's window so linearly interpolating did not introduce any additional data). Once the smooth $\tilde{q}_{\gamma_{n}}$ was calculated and its mean removed, we used potential thickness anomalies, time-mean removed, (see figure 7) to investigate density changes in the LSW.

In the time series of potential thickness anomalies, recently ventilated waters appeared as positive features (water less stratified than the mean) coherent (vertically) in space as well as in time. We took the zero anomaly contour, $\tilde{q}_{\gamma_{n}}^{\prime}=0$, as the boundary between the layers. Features whose depth core was located between 500 and $1000 \mathrm{~m}$ trace the evolution of uLSW, while features between 1000 and $2500 \mathrm{~m}$ are dLSW. Below was the OW. These boundaries are approximate, not always clearly defined and can sometimes overlap. The properties at the $\tilde{q}_{\gamma_{n}}^{\prime}$ minimum and the thickness of the layers bounded by the zero contour experienced large variations. The core of newly 
ventilated dLSW deepened by about 500m, from $1500 \mathrm{~m}$ where it was found in 2001 to approximately $2000 \mathrm{~m}$ in 2003. This change in depth was accompanied by the corresponding change in density, going from $\gamma_{n}=27.95 \mathrm{~kg} / \mathrm{m}^{3}$ in 2001 to $\gamma_{n}=28 \mathrm{~kg} / \mathrm{m}^{3}$ in 2003 . We note that the latter value is larger than the lower boundary of the dLSW used in the previous transport calculation. This suggests that, at times, up to $25 \%$ of our dLSW transport estimate could be mis-assigned to OW. The thickness of the uLSW as seen in figure 7 was also larger than the thickness of the layer based on the fixed density boundaries. So its transport could be underestimated as well.

The evolution of PPV in Z-coordinates shown in Figure 2 suggested that the two types of LSW at W3 alternate throughout the record. The same is evident in density coordinates, however the transition between the dLSW and uLSW is much more abrupt than seen in Z-coordinates, indicating that the PPV changes during the transition were caused by the isopycnal heaving rather than changes within a density class. Both of these views, $\mathrm{Z}$ and density coordinates, are in good agreement with the conditions observed in the Labrador Sea half a decade earlier. According to Yashayaev (2007), strong convection in the Labrador Sea stopped in 1994, at which time the LSW was its densest and most voluminous. The densest LSW was observed at Line $\mathrm{W}$ in 2003, implying a spreading time for the dLSW of 9 years. However, due to the finite length of the record, this value should only be considered as an upper bound. Once the strong convection ceased in the Labrador Basin, the weaker convection responsible for the formation of uLSW did not start until the winter of 2000. By 2003 the uLSW reached its maximum thickness in the Labrador Sea, and 4 to 5 years later, in 2007, this thick layer of 
uLSW was observed at Line W. Thus the spreading time of the uLSW lies somewhere between 4 , when the peak of uLSW layer thickness is used as the starting time, and 7 years, if the onset of convection is used instead. The latter understood as the arrival of the fastest (first originated) signal from the Labrador Sea. However, the accuracy of these spreading times, and we believe others too, depends upon our ability to define extrema and inflection points both in our record as well as in the available records in the Labrador Sea. The recent work by Rhein et al. (2011) shows a continuous increase in the uLSW layer thickness with only a small peak (not significant within the error bars) in 2000 corresponding to the start of convection. Their estimates, being based on fixed-density ranges, are not so straight forward to compare with our PV-based calculation, but nevertheless point out the "only approximate" nature of the spreading time estimates presented here.

One last interesting aspect seen in the evolution of layer stretching anomalies is the out-of-phase relation found between OW and dLSW. Because these water masses are formed in different locations, the formation of the one should a priori not impact the formation of the other, as is the case for upper and deep LSW. However, it is possible that as the dLSW layer expands, it occupies the upper part of the OW depth range. The OW, whose lower boundary is practically at the bottom at W3, might then be forced offshore or takes an alternative equatorward route through the interior. This would also explain why the transition between OW and dLSW is so abrupt. As soon as the dLSW layer vanishes at W3, the OW layer develops again. 


\section{Summary and discussion}

In the present study we explored changes in the properties of the LSW within the DWBC southeast of Cape Cod for the period of November 2001 to May 2008. The most significant of the observed property changes occurred in the PPV field. The PPV minimum that traces the core of the waters formed by convection in the Labrador and Irminger Basins, slowly migrated from a depth of $1500 \mathrm{~m}$, where dLSW is typically found, to $700 \mathrm{~m}$, typical of uLSW. Between 2001 and 2003, the PPV anomaly minimum was deeper in the water column and more pronounced. After 2003 the PPV signal became more diffuse, and it was not until 2006 when the PPV minimum migrated to the uLSW level that a distinct PPV anomaly minimum was observed again. The transition between the two types of LSW corresponded to a period when moderate convection was observed in the Labrador Basin (Schott et al. (2004) and Yashayaev (2007)). Over time, the water re-stratified and its signature as it propagated equatorward was seen at Line $\mathrm{W}$ in the gradual rising of the isopycnals between 2003 and 2006. A description of the changes occurring in the newly ventilated LSW was obtained by working in isopycnal coordinates to remove the effects of isopycnal heaving. We found that during the intensification of the deep PPV minimum in the early part of the record, the dLSW layer was expanding, and the stratification within it was decreasing. The layer reached maximum density and thickness values around 2003. After 2004, the stratification in the dLSW increased and the uLSW layer started to develop. By 2007 the dLSW thickness reached a minimum, and the uLSW layer was fully developed.

The evolution of the layer thickness and density of both types of LSW 
agrees remarkably well with that seen in the central Labrador Sea during the 1990s (Yashayaev (2007)), albeit later in time. The time difference between the potential vorticity minima observed in the central Labrador Sea and at Line W suggested that the two types of LSW had somewhat different spreading rates during the observation period. Anomalies in dLSW took approximately 9 years to propagate from the central Labrador Sea to Line $\mathrm{W}$, which implies a spreading rate of approximately $1.5 \mathrm{~cm} / \mathrm{s}$, this being a lower bound estimate for the spreading rate since 9 years corresponds to the upper bound for the spreading time. The uLSW anomalies on the other hand appeared to spread more rapidly, taking between 4 and 7 years to reach Line $\mathrm{W}$ depending on whether maximum uLSW or onset of convection in the Labrador Sea are employed as starting time. This translates into spreading rates ranging from 2 to $3 \mathrm{~cm} / \mathrm{s}$. These spreading rates are in much better agreement with those estimated by Molinari et al. (1998) than with the earlier estimates by Smethie (1993). Molinari et al. (1998) analyzed tracer data from a series of hydrographic sections across the DWBC at $26.5^{\circ} \mathrm{N}$, and estimated a transit time for the LSW from the Labrador Sea of 10 years, which implies a spreading speed of $2.5 \mathrm{~cm} / \mathrm{s}$, similar to what is found here for the uLSW. Smethie (1993) inferred spreading rates from CFC inventories that are one order of magnitude lower than ours. His numbers range from $11-12$ years at $45^{\circ} \mathrm{N}$ to 18 years at $32^{\circ} \mathrm{N}$. However, those previous estimates were based on a limited number of bottle measurements, compared to our continuous mooring record, and the uncertainties associated with the exact arrival time of the signals could be large. In that regard, we believe our estimate might be more accurate, since we were able to observe the exact 
time of the transition between the dLSW and the uLSW.

Along with the density and layer thickness variations, we found that on average, the water at W3 became colder and fresher with time. However, within the dLSW depth range, this tendency was reversed. The water here became warmer and saltier over time, similar to what was found by Yashayaev (2007) in the central Labrador Sea.

Simple inspection of these anomaly time series suggested that the variability in the velocity field was not closely coupled with the variability in the stratification. Fluctuations in the velocity field were more rapid than those seen in the hydrography. The joint EOF of the temperature, salinity and velocity anomaly fields revealed that the fraction of the velocity variability that correlates with water mass changes was rather small (about 10\% of the full velocity variability), with amplitudes of just $0.5-1 \mathrm{~cm} / \mathrm{s}$. Nevertheless, the sense of the correlated part was such that when newly ventilated dLSW was exported (PPV anomaly was negative at the dLSW level), the mean southwestward flow became stronger in the bottom $500 \mathrm{~m}$ but weaker everywhere above it. At times when the negative PPV anomaly was in the uLSW, the mean southwestward flow was greater. These changes in the velocity field were consistent with the spreading rates inferred from the arrival of PPV and potential thickness anomalies to Line W, with the uLSW spreading nearly twice as fast as the dLSW. The vertical shear in the mean velocity profile, decreasing velocity with increasing depth, also contributed to the faster spreading of the uLSW, and further enhanced the difference in the spreading rates of both types of LSW. The in-phase/out-of-phase nature of the relationships between the density and velocity fields in the uLSW 
and dLSW captured by the EOF analysis resulted in a partial compensation of the transport per unit width of the two types of LSW at W3. Using fixed-density ranges to define both LSW types, we found that $25 \%$ of the transport per unit width variability at W3 was due to changes in layer thickness. These changes in layer thickness were responsible for the compensation between uLSW and dLSW above mentioned. The remaining $75 \%$ was related to changes in the velocity averaged across the layer. In the uLSW, the contribution of the changing velocity term together with the increasing layer thickness resulted in an overall transport change of about - $0.15 \mathrm{~Sv}$, if the pointwise changes hold over a total width of the flow of $100 \mathrm{~km}$. In the dLSW, some of the acceleration of the southwestward flow was canceled by the decreasing layer thickness, leading to a net transport change of $-0.2 \mathrm{~Sv}$ (again assuming $100 \mathrm{~km}$ width). These transport changes are small compared to the transport variability in the DWBC found by others. Bryden et al. (2005) found that the transport of the synoptic DWBC at $26.5^{\circ} \mathrm{N}$ ranges from 5 to $75 \mathrm{~Sv}$. Similar values, and more relevant to the work presented here, were reported by Toole et al. (2011) using the full Line W moored array data for the period of 2004-2008. However, the EOF velocity mode used in the present transport calculation represented just 10\% of the full DWBC velocity variability. Using the full velocity variability (typical changes of $\pm 15 \mathrm{~cm} / \mathrm{s}$ ), the transport variability obtained would be one order of magnitude larger $(-1.5 \mathrm{~Sv}$ for the uLSW and $-2 \mathrm{~Sv}$ for the dLSW), comparable to the amplitude of the response of the LSW transport to changes in the MOC found by Böning et al. (2006) but still smaller to that reported by Bryden et al. (2005) and Toole et al. (2011). The latter found that transport variations in 
the DWBC are dominated by width and velocity fluctuations, rather than by changes in the layer thickness. Because of the one-dimensional nature of the W3 observations, the effect of changes in the lateral extent of the DWBC cannot be considered here. However, this and other aspects of the variability in the flow of the DWBC associated with lateral changes in the DWBC were addressed in Pena-Molino (2010). The analysis of four years of data of the full Line $\mathrm{W}$ array (of which W3 is the central mooring) showed that the flow structure and the variability in the hydrographic properties during the study period had a different character inshore and offshore of the $3500 \mathrm{~m}$ isobath. With the transition between these two regimes located slightly offshore from W3, the analysis presented here is more representative of the variability in the inner Slope (depths smaller than 3500m). The layered structure observed in PV was, on the other hand, coherent throughout the array, and exhibited the same phase relation between the different types of LSW reported here.

The work presented here suggests that the DWBC is an active pathway for the export of LSW, not only in the mean but for the variability as well. The apparent contradiction between the Lagrangian view provided by the floats (Fischer and Schott (2002), Bower et al. (2009) and Bower et al. (2011)) and the Eulerian description of the variability based on the evolution of the PPV provided here as well as the water mass age distribution inferred from CFCs by Fine et al. (2002), can be in part explained by the different nature of the processes that govern the motion of the floats versus the spreading of a water mass inferred from a tracer. The motion of the floats is a purely advective process in which the displacements of a water parcel, whose properties are changing due to mixing, are determined by the instantaneous velocity field. 
The spread of a tracer, on the other hand, is the result of an advectivediffusive balance. In this balance the mean flow, or the slowly varying part of it, is responsible for the advection of the tracer along the DWBC, while the integrated effect of the eddies acts to pull the tracer away from the boundary and into the interior. This was shown in the Getzlaff et al. (2006) simulated float trajectories. When the mean circulation was considered, $90 \%$ of the floats that were deployed in the Labrador Sea and reached the subtropics did so via the classical path in the DWBC, whereas only $60 \%$ followed this path when the variability was used instead. In a similar experiment by Bower et al. (2011), the percentage of floats exported via the DWBC in the mean was smaller than that of Getzlaff et al. (2006), however, still larger than the contribution from the interior pathway in the mean. In addition, another aspect of the circulation of LSW that cannot be captured by the floats is that related to the changes in the density of the water that is formed in the Labrador Sea from year to year. As was shown here, these changes in density are associated with large changes in the core depth of the LSW. This temporal variability was not accounted for by the isobaric floats, that were deployed at the same location and depth throughout the entire Bower et al. experiment.

If the spreading of the tracer core, in this case PPV, along the DWBC route represents the less frequent export of the undiluted LSW, while the behavior of the floats is, on the other hand, representative of the more frequent interior transport of more diluted LSW, it is natural to ask which of the two pathways is exporting more LSW? This question can only be addressed from a modeling perspective. However, the ability of current-generation models to 
form the right volume of water with the correct characteristics is debatable; the answer one obtains from them may not necessary be accurate or even reproducible across models.

\section{Acknowledgments}

Financial support for the early observations (2001-2004) was provided by the G. Unger Vetlesen Foundation. Observations collected as part of the Line W program (2004-2008) were funded by the U.S. National Science Foundation (grants number OCE-0241354 and OCE-0726720) as well as funding from WHOI's Ocean and Climate Change Institute. We would also like to thank Amy S. Bower, Michael A. Spall and John Marshall for their comments on an earlier version of the manuscript, as well as two anonymous reviewers.

\section{References}

Bailey, D.A., Rhines, P.B., Hakkinen, S., 2005. Formation and pathways if the North Atlantic Deep Water in a couple ice-ocean model of the Arctic-North Atlantic Oceans. Climate Dynamics 25, 497-516. Doi:10.1007/s00382-005-0050-3.

Böning, C.W., Scheinert, M., Dengg, J., Biastoch, A., Funk, A., 2006. Decadal variability of subpolar gyre transport and its reverberation in the North Atlantic overturning. Geophysical Research Letters 33. Doi:10.1029/2006GL026906.

Bower, A.S., Hunt, H.D., 2000. Lagrangian Observations of the Deep Western Boundary Current in the North Atlantic Ocean. Part I: Large-scale 
pathways and spreading rates. Journal of Physical Oceanography 30, 764783.

Bower, A.S., Lozier, M.S., Gary, S.F., Böning, C.W., 2009. Interior pathways of the North Atlantic meridional overturning circulation. Nature 459. Doi:10.1038/nature07979.

Bower, A.S., Lozier, S., Gary, S., 2011. Export of labrador sea water from the subpolar north atlantic: A lagrangian perspective. Deep-Sea Research II in press. Doi:10.1016/j.dsr2.2010.10.060.

Brown, O.B., Cornillon, P.C., Emmerson, S.R., Carle, H.M., 1986. Gulf stream warm rings: a statistical study of their behavior. Deep-Sea Research 33, 1459-1473.

Bryden, H.L., Johns, W.E., Saunders, P.M., 2005. Deep western boundary current east of Abaco: mean structure and transport. Journal of Marine Research 63, 35-57. Doi:10.1357/0022240053693806.

Fine, R.A., Rhein, M., Andrie, C., 2002. Using a cfc effective age to estimate propagation and storage of climate anomalies in the deep western north atlantic ocean. Geophysical Research Letters 24. Doi:10.1029/2002GL015618.

Fischer, J., Schott, F.A., 2002. Labrador Sea Water Tracked by Profiling Floats-From the Boundary Current into the Open North Atlantic. Journal of Physical Oceanography 32, 573-584.

Flagg, C.N., Dunn, M., Wang, D.P., Rossby, H.T., Benway, R.L., 2006. A study of the currents of the outer shelf and upper slope from a decade 
of shipboard adcp observations in the middle atlantic bight. Journal of Geophysical Research 111. Doi:10.1029/2005GJC003116.

Fratantoni, P.S., Pickart, R.S., 2003. Variability of the shelf break jet in the Middle Atlantic Bight: Internally or externally forced? Journal of Geophysical Research 108. Doi:10.1029/2002JC001326.

Getzlaff, K., Böning, C.W., Dengg, J., 2006. Lagrangian perspectives of deep water export from the subpolar north atlantic. Geophysical Research Letters 33. Doi:10.1029/2006GL026470.

Joyce, T.M., Dunworth-Baker, J., Pickart, R.S., Torres, D., Waterman, S., 2005. On the Deep Western Boundary Current south of Cape Cod. DeepSea Research II 52, 615-625.

Kieke, D., Klein, B., Stramma, L., Rhein, M., Koltermann, K.P., 2009. Variability and propagation of labrador sea water in the southern subpolar north atlantic. Deep-Sea Research I 56, 1656-1674.

Kieke, D., Rhein, M., Stramma, L., Smethie, W.M., Bullister, J.L., Lebel, D.A., 2007. Changes in the pool of labrador sea water in the subpolar north atlantic. Geophysical Research Letters 34. Doi:10.1029/2006GL028959.

Kieke, D., Rhein, M., Stramma, L., Smethie, W.M., Lebel, D.A., Zenk, W., 2006. Changes in the cfc Inventories and Formation Rates of Upper Labrador Sea Water, 1997-2001. Journal of Physical Oceanography 36, 64-86.

Lee, T.N., Johns, W.E., Zantopp, R.J., Fillenbaum, E.R., 1996. Moored observations of Western Boundary Current Variability and Thermohaline 
Circulation at 26.5N in the Subtropical North Atlantic. Journal of Physical Oceanography 26, 962-983.

Mauritzen, C., Häkkinen, S., 1999. On the relationship between dense water formation and the Meridional Overturning Cell in the North Atlantic Ocean. Deep-Sea Research I 46, 877-894.

Molinari, R.L., Fine, R.A., Wilson, W.D., Curry, R.G., Abell, J., McCartney, M.S., 1998. The arrival of recently formed Labrador sea water in the Deep Western Boundary Current at 26.5N. Geophysical Research Letters 25, 2249-2252.

North, G.R., 1984. Empirical orthogonal functions and normal modes. Journal of the Atmospheric Sciences 41, 879-887.

Pena-Molino, B., 2010. Variability in the North Atlantic Deep Western Boundary Current: upstream causes and downstream effects as observed at Line W. Ph.D. thesis. MIT/WHOI Joint Program in Physical Oceanography.

Pickart, R.S., 1992. Water mass components of the North Atlantic deep western boundary current. Deep-Sea Research 39, 1553-1572.

Pickart, R.S., 1994. Interaction of the Gulf Stream and the Deep Western Boundary Current where they cross. Journal of Geophysical Research 99, $25155-25164$.

Pickart, R.S., Smethie, W.M., 1993. How Does the Deep Western Boundary Current Cross the Gulf Stream? Journal of Physical Oceanography 23, $2602-2616$. 
Pickart, R.S., Smethie, W.M., 1998. Temporal evolution of the deep western boundary current where it enters the sub-tropical domain. Deep-Sea Research Part I 45, 1053-1083.

Pickart, R.S., Smethie, W.M., Lazier, J.R.N., Jones, E.P., Jenkins, W.J., 1996. Eddies of newly formed upper Labrador Sea Water. Journal of Geophysical Research 101, 20711-20726.

Pickart, R.S., Spall, M.A., Lazier, J.R.N., 1997. Mid-depth ventilation in the western boundary current system of the sub-polar gyre. Deep-Sea Research I 44, 1025-1054.

Pickart, R.S., Watts, D.R., 1990. Deep Western Boundary Current Variability at Cape Hatteras. Journal of Marine Research 48, 765-791.

Rhein, M., Fischer, J., Smethie, W.M., Smythe-Wright, D., Weiss, R.F., Mertens, C., Min, D.H., Fleischmann, U., Putzka, A., 2002. Labrador Sea Water: Pathways, CFC Inventory, and Formation Rates. Journal of Physical Oceanography 32, 648-665.

Rhein, M., Kieke, D., Hüttl-Kabus, S., Roessler, A., Mertens, C., Meissner, R., Klein, B., Böning, C.W., Yashayaev, I., 2011. Deep water formation, the subpolar gyre, and the meridional overturning circulation in the subpolar north atlantic. Deep Sea-Research II in press. Doi:10.1016/j.dsr2.2010.10.061.

Rhein, M., Kieke, D., Steinfeldt, R., 2007. Ventilation of the Upper Labrador Sea Water, 2003-2005. Geophysical Research Letters 34. Doi:10.1029/2006GL028540. 
Schott, F.A., Fischer, J., Wibaux, M., Dengler, M., Zantopp, R., 2006. Variability of the Deep Western Boundary Current east of the Grand Banks. Geophysical Research Letters 33, L21S07.

Schott, F.A., Zantopp, R., Stramma, L., Dengler, M., Fischer, J., Wibaux, M., 2004. Circulation and Deep-Water Export at the Western Exit of the Subpolar North Atlantic. Journal of Physical Oceanography 34, 817-843.

Silverthorne, K.E., Toole, J.M., 2009. Seasonal kinetic energy variability of near-inertial motions. Journal of Physical Oceanography 39, 1035-1049. Doi:10.1175/2008JPO3920.1.

Smethie, W.M., 1993. Tracing the thermohaline circulation in the western North Atlantic using chlorofluorocarbons. Progress in Oceanography 31, 51-99.

Stommel, H., 1958. The abyssal circulation. Deep-Sea Research (Letters) 5, $80-82$.

von Storch, H., Zwiers, F.W., 1999. Statistical Analysis in Climate Research. Cambridge University Press.

Stramma, L., Kieke, D., Rhein, M., Schott, F., Yashayaev, I., Koltermann, K.P., 2004. Deep water changes at the western boundary of the subpolar North Atlantic during 1996 to 2001. Deep-Sea Research I 51, 1033-1056.

Swallow, J., Worthington, L., 1961. An observation of a deep countercurrent in the western North Atlantic. Deep-Sea Research 8, 1-19. Doi:10.1016/0146-6313(61)90011-9. 
Talley, L.D., McCartney, M.S., 1982. Distribution and circulation of Labrador Sea water. Journal of Physical Oceanography 12, 1189-1204.

Thompson, R., Luyten, J.R., 1976. Evidence for bottom-trapped topographic rossby waves from signel moorings. Deep-Sea Research 23, 629-635.

Toole, J.M., Curry, R.G., Joyce, T.M., McCartney, M., Pena-Molino, B., 2011. Transport of the North Atlantic Deep Western Boundary Current about 39N, 70W: 2004-2008. Deep Sea-Research II in press. Doi:10.1016/j.dsr2.2010.10.058.

Vaughan, S.L., Molinari, R.L., 1997. Temperature and Salinity Variability in the Deep Western Boundary Current. Journal of Physical Oceanography 27, 749-761.

Watts, D.R., Johns, W.E., 1982. Gulf Stream Meanders: Observations on Propagation and Growth. Journal of Geophysical Research 87, 9467-9476.

Worthington, L.V., 1976. On the North Atlantic Circulation. The Johns Hopkins Oceanographic Studies.

Yashayaev, I., 2007. Hydrographic changes in the Labrador Sea, 1960-2005. Progress in Oceaongraphy 73, 242-276.

Yashayaev, I., Bersch, M., van Aken, H.M., 2007. Spreading of the Labrador Sea Water to the irminger and iceland basins. Geophysical Research Letters 34. Doi:10.1029/2006GL028999. 